\title{
Chemical Composition and Antibacterial Activity of Essential Oils Extracted from Plants Cultivated in Mexico
}

\author{
Crescencio Rodriguez Flores, ${ }^{\mathrm{a}}$ Alizé Pennec, ${ }^{\text {,c }}$ Caroline Nugier-Chauvin, ${ }^{\mathrm{b}, \mathrm{c}}$ Richard Daniellou, ${ }^{\mathrm{d}}$ Luis
} Herrera-Estrella, ${ }^{a}$ and Anne-Laure Chauvin ${ }^{\mathrm{a}, *}$

a Laboratorio Nacional de Genómica para la Biodiversidad (Langebio), CINVESTAV-IPN, Km 9.6 Lib. Nte, Carr. IrapuatoLeón, CP36821, Irapuato, México.achauvin@langebio.cinvestav.mx

b Ecole Nationale Supérieure de Chimie de Rennes, CNRS, UMR 6226, Avenue du Général Leclerc, CS 50837, 35708 Rennes Cedex 7, France.

c Université Européenne de Bretagne, France.

d Institut de Chimie Organique et Analytique, Université d'Orléans, CNRS, UMR7311, BP 6759, Rue de Chartres, 45067 Orléans Cedex 2, France.

Received February $4^{\text {th }}, 2014$; Accepted July 30 ${ }^{\text {th }}, 2014$

\begin{abstract}
Samples of lavender, rosemary and laurel essential oils obtained from plants cultivated in Mexico were analysed by GC-MS using a non polar capillary column. Characterisation of individual components was performed using a commercial mass spectrometry library, and 53 components were identified. The analysis of bioactive compounds highlighted a 5 and 2-fold increased quantity of potent antibacterial 1,8-cineole (46.5\%) and camphor (12.3\%) in lavandin "provence", compared to the French cultivars. It also showed a 3- and 2 -fold increase in camphor and linalool concentration in rosemary and laurel compared to the average level, making them promising alternatives for medicinal treatment. Strains of Gram-positive and Gram-negative bacteria were analyzed for their susceptibility to these essential oils using the agar disc diffusion method and their antimicrobial activity was demonstrated. To our knowledge, this is the first report on antibacterial activity of lavender essential oil, recently added to the Mexican pharmacopeia, against Mycobacterium smegmatis (Mc Rv 3782 PW2).

Key words: essential oil; lavender; antimicrobial activity; bioactive compound; GC-MS; Mycobacterium smegmatis.
\end{abstract}

\section{Introduction}

Monoterpenes are a class of volatile organic compounds whose, with others, are responsible for the main medicinal and olfactory properties of essential oils (EOs). 1,8-cineole, cis- and trans- $\beta$-ocimene, terpinen-4-ol, camphor, linalool and linalyl acetate are part of those forty to fifty bioactive molecules that can usually be identified by gas chromatography - mass spectrometry analysis (GC-MS) in EOs. The proportion of these compounds usually determines the quality of EOs used as perfumery standards (high content of linalool and linalyl acetate combined with trace amount of camphor) or as medicinal standards (high contents of bioactive monoterpenes) [1-7].

The composition of essential oils depends on several factors such as plant genotype, the developmental stage of the plant and the environmental factors [8]. Lavandula $x$ intermedia (Lavandin) is characterized by a high 1,8-cineole and
Resumen. Diversas muestras de aceites esenciales de lavanda, romero y laurel fueron obtenidas de plantas cultivadas en México y analizadas por GC-MS usando una columna capilar no-polar. La caracterización de los compuestos individuales se realizó utilizando una biblioteca comercial para espectrometría de masa y fueron identificados 53 compuestos. Este análisis demostró un incremento de 5 y 2 veces de los compuestos bioactivos 1,8-cineol (46.5\%) y alcanfor $(12.3 \%)$, respectivamente, en la lavanda "provence" comparada con cultivos franceses. Además, se observó un incremento de 3 y 2 veces en la concentración de alcanfor y linalool, respectivamente, en romero y laurel en comparación con concentraciones medias conocidas, convirtiéndolos en buenas alternativas para tratamientos medicinales. Finalmente, se analizó la susceptibilidad de varias cepas de bacterias de Gram positivas y Gram negativas a estos aceites esenciales a través del método de difusión en disco de agar, y se comprobó su actividad antibacteriana. Dentro de nuestro conocimiento, esta es la primera vez que se reporta actividad antibacteriana en el aceite esencial de lavanda, que recientemente se ha incorporado a la farmacopea mexicana en contra de Mycobacterium smegmatis (Mc Rv 3782 PW2).

Palabras claves: aceite esencial; lavanda; actividad antimicrobiana; compuestos bioactivos; GC-MS; Mycobacterium smegmatis.

camphor content, which denotes a low quality of oil according to perfumery standards, but is of interesting value as medicinal oil. Lavandin EOs are readily available in many areas of the world and particularly in the region of Dolores Hidalgo (Guanajuato), where the results of this investigation will be applied. Therefore, the aim of this investigation was to analyze the chemical composition and major bioactive compounds of lavender essential oils made from Lavandula $x$ intermedia "provence" and "grosso" cultivated in Mexico. Rosmarinus officinalis L. (rosemary) and Laurus nobilis L. (laurel) essential oils obtained from plants cultivated in the same area were also investigated. Additionally, the inhibitory effects of the essential oils towards Gram-negative (Escherichia coli BL21 DE3) and Gram-positive (M. smegmatis Mc Rv 3782 PW2) bacteria were studied. Although M. smegmatis is a non-pathogenic model of Mycobacterium tuberculosis, its study can be useful in combating the increased resistance of $M$. tuberculosis to existing TB drugs $[9,10]$. 


\section{Results and discussion}

Chemical characterisation - The result of the analysis of the major bioactive components of Lavandula $x$ intermedia "grosso" and "provence", natural hybrids of L. angustofolia and L. latifolia, laurel and rosemary cultivated in Mexico is presented in table 1 and their chromatographs can be found in supplementary information (chromatographs 1a to 1e). The qualitative characterisations were performed using GC-MS and 53 components in the samples were characterized, including 1,8-cineole, cis- and trans- $\beta$-ocimene, terpinen-4-ol, camphor, borneol, linalool and linalyl acetate.

These data were compared to values obtained for the same species cultivated in different parts of the world [11, 12] and the most recent international reference ISO published on the area (ISO 8902-2007) [13]. The remarkable effect of the geographical region on the concentration of terpenes [14] was demonstrated by the variation in the bioactive compound concentration in the Mexican species.

It was noticed that the contents of linalool and linalyl acetate were higher in the Mexican lavandin "grosso" and lower in the Mexican lavandin "provence" compared to the data reported elsewhere $[11,12,15]$. To our knowledge, there is only one report on the GC-MS analysis of lavandin "provence" in the literature [12] while several were published on lavandin "grosso" $[11,13,15]$. In laurel essential oil, the concentration of linalool was higher than the one present in laurel EOs from other regions of the world (up to 15 times higher) [16, 17]. By contrast, no linalyl acetate was detected in laurel and rosemary EOs.

1,8-Cineole concentration was higher in Mexican lavenders compared to that reported for species grown in France whereas the concentration of camphor was relatively similar in samples obtained from both growth regions $[11,12,15]$. Indeed, in the species Lavandula x intermedia "provence", the impact of the geographical growth region led to a 5-fold higher level of 1,8cineole and a 2-fold higher level of camphor compared with published data. Moreover, it was observed that the 1,8-cineole content between the Lavandula x intermedia "provence" and "grosso" was drastically different, $46.52 \%$ and $7.49 \%$ respectively (table 1). The analysis of rosemary EOs exhibited important differences in the concentration of the previously mentioned bioactive compounds [18-20] and the apparent most interesting area for growing rosemary for camphor production appeared to be Mexico with a concentration of $18.8 \%$.

Antibacterial activities - EOs have found medicinal applications as an alternative or parallel treatment for tuberculosis [21, 22], cancer [23] or influenza [24] to name but a few [25].

Table 2 shows the antibacterial activity of Mexican essential oils either as crude or diluted distilled products on a Grampositive (M. smegmatis Mc Rv 3782 PW2) and a Gram-negative (E. coli BL21 DE3). Both bacteria exhibited significant susceptibility when treated with all tested EOs presenting an inhibition diameter of more than $10 \mathrm{~mm}$, (suppl. Information, $2 \mathrm{a}$ and $2 \mathrm{~b}$ ).

The disc diffusion method was applied to measure the antibacterial action of the EOs on the selected bacteria. It supported the previous results obtained for rosemary EOs having a better potential as antibacterial agent against Gram-negative bacteria than Gram-positive [24-27]. Dilution of the crude rosemary EOs did not improve the inhibitory capacity of the oil against E. coli. Laurel EOs were also tested as an antibacterial agent against Gram-positive and Gram-negative bacteria under similar conditions and M. smegmatis Mc Rv 3782 PW2 appeared to be slightly more resistant than E. coli BL21 DE3 to laurel EOs inhibition. The methanolic laurel solution better inhibited the

Table 1. Relative concentration of major monoterpenes obtained by GC-MS (\%) essential oils from plant cultivated in Mexico. n.d.: none detected.

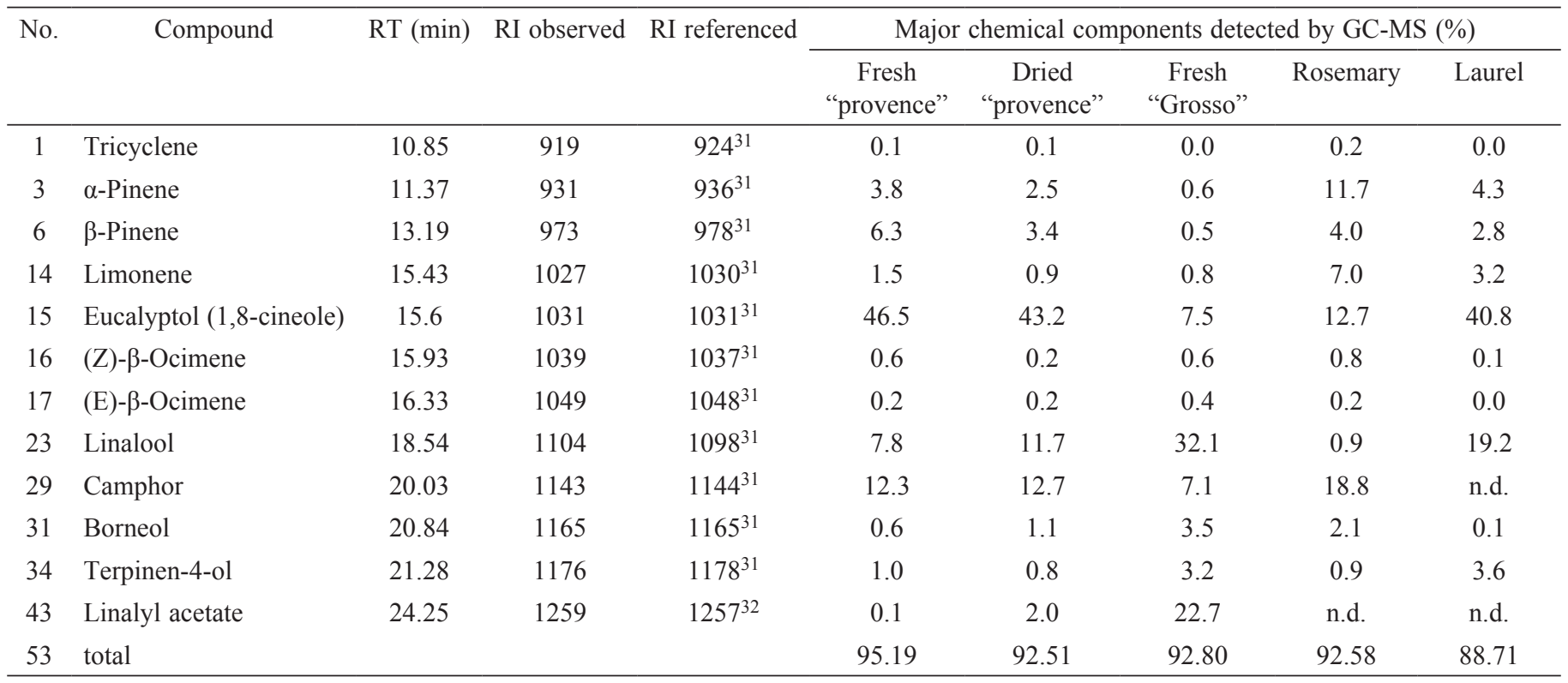


Table 2. Antibacterial activity of essential oils $(5 \mu \mathrm{L})$ towards gram-positive and gram-negative bacteria.

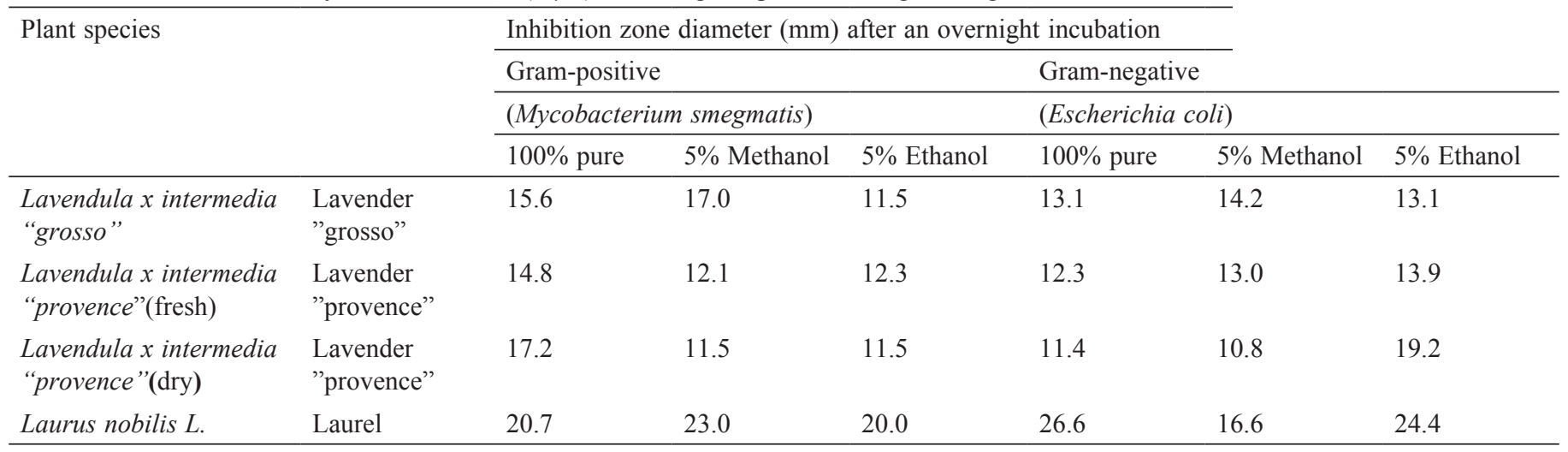

*The diameter of the filter paper disc $(4 \mathrm{~mm})$ is included. No inhibition $(<4 \mathrm{~mm})$.

Gram-positive bacteria whereas it resulted in an opposite effect for Gram-negative bacteria. The ethanolic diluted mixture had a limited response.

The inhibitory capacity of crude lavender EOs towards gram-negative $E$. coli BL21 DE3 was affected by the plant varieties and the dilution solvent (table 2). This diversity in the antibacterial response can be explained by the difference in the chemical composition of each essential oil; indeed, a higher content of linalool and linalyl acetate is observed for lavender "grosso" EOs compared to lavender "provence" EOs, whereas an opposite trend is observed for bioactive compounds cineole and camphor. Finally, to our current knowledge, this was the first report of lavender EOs being assayed for antibacterial activity towards M. smegmatis Mc Rv 3782 PW2.

In conclusion, the analysis of the chemical composition of EOs from plants cultivated in Mexico highlighted a high content of bioactive compounds: linalool, linalyl acetate, cineole and camphor, making them promising alternatives for medicinal treatments. The results of lavender EOs inhibition activity towards M. smegmatis Mc Rv 3782 PW2 and E. coli BL21 DE3 suggested that Gram-positive bacteria are more sensitive than Gram-negative bacteria to plant distilled products [28, 29]. Adding ethanol and methanol to the crude distilled product had a relative to significant effect on the inhibitory activity. To our knowledge and for the first time, the antibacterial activity of lavender essential oils against M. smegmatis Mc Rv 3782 PW2 Gram-positive bacteria was reported.

\section{Material and methods}

Chemical and reagents - Lavender and rosemary essential oils were diluted in ethanol (1:100) and laurel essential oils were diluted in ethanol $(1: 250)$ for GC-MS analysis. Ethanol and methanol of HPLC grade were used for dilution, chromatography and antibacterial analysis.

Essential oils - The following lavender, rosemary and laurel oils, a gift the Azul Lavanda, S.P.R. in Dolores Hidalgo, Mexico, were used in this study: Provence (Lavandula $x$ intermedia, blue lavandin), Grosso (Lavandula $x$ intermedia, purple lavandin), Rosmarinus officinalis L. (rosemary) and Laurus nobilis L. (laurel). All lavender, rosemary and laurel oils were obtained by steam distillation (temperature: $120{ }^{\circ} \mathrm{C}$, pressure: 5 PSI, distillation time: $3 \mathrm{~h}$ ) of the fresh material of the respective plant species and the essential oils were stored in the dark. The lavender plants were grown under natural conditions as a field site in Dolores Hidalgo, Guanajuato, Mexico. The site was located at approximately $21.17^{\circ} \mathrm{N}, 100.93{ }^{\circ} \mathrm{W}$ and an altitude of approximately $1,980 \mathrm{~m}$. According to recommendations, individual plants were spaced $1 \mathrm{~m}$ apart, watered every 15 days for 8 to $12 \mathrm{~h}$ (drip irrigation) and no fertilised agent was used.

GC-MS analysis - Gas Chromatographic analysis were carried out on an Agilent 6890N system (Agilent Technologies, U.S.A.), equipped with Chemstation software and coupled to a mass spectrometer detector (Agilent 5975B). An analytical HP-5MS column $(30 \mathrm{~m} \times 0.25 \mathrm{~mm}$ I.D. $\times 5 \mu \mathrm{m}$ film thickness) from Agilent Technologies was used for chromatographic separation. GC-MS spectra were obtained using the following conditions: the vector gas was helium at a constant flow of $1 \mathrm{~mL} / \mathrm{min}$, the injection was made in split mode $(10: 1)$, the injection volume was $1 \mu \mathrm{L}$ and the injector temperature was $260{ }^{\circ} \mathrm{C}$. The oven temperature program was: $40{ }^{\circ} \mathrm{C}$ for $5 \mathrm{~min}$, then increased at $4{ }^{\circ} \mathrm{C} / \mathrm{min}$ to $200{ }^{\circ} \mathrm{C}$ over $5 \mathrm{~min}$ and then at $20{ }^{\circ} \mathrm{C} / \mathrm{min}$ to $280{ }^{\circ} \mathrm{C}$ for $1 \mathrm{~min}$. The ionisation mode was electronic impact at $70 \mathrm{eV}$ in positive mode and the signal acquisition was the scan mode from 40 to 400 . The MS source was at $230{ }^{\circ} \mathrm{C}$ and the MS quad at $150{ }^{\circ} \mathrm{C}$. GC-MS data were processed using AMDIS (Automatic mass spectral deconvolution and identification system, provided by US National Institute of Standards and Technology, Gaithesburg, MD, USA). The chromatographs can be found in supplementary information (chromatograph 1a to 1e).

Identification of essential oil components - Essential oil components were identified by comparison of their mass spectral fragmentation pattern with NIST mass spectral library database [30] and based on their Van Den Dool retention indices (determined with reference to a homologous series of normal alkanes, C7-C40, and compared with the ones reported in literature) [31, 32]. As expected, there are still some compounds that could not be identified because of their low signal-to-noise ratios or 
limitation of the mass spectral database. Relative area of each essential oil component was carried out by a peak area normalization measurement total ion current [31,32].

Antibacterial analysis - $5 \mathrm{~mL}$ of Lysogeny Broth medium supplemented with $50 \mu \mathrm{g} / \mathrm{mL}$ kanamycine were inoculated with $20 \mu \mathrm{L}$ Escherichia coli (BL21 DE3, Gram negative) or $20 \mu \mathrm{L}$ Mycobacterium smegmatis (Mc Rv 3782 PW2, Gram positive), and incubated overnight at $37{ }^{\circ} \mathrm{C}, 160 \mathrm{rpm} .200 \mu \mathrm{L}$ of these cultures were spread over solidified LB medium containing kanamycine $(50 \mu \mathrm{g} / \mathrm{mL})$, using a sterile rod in order to get a uniform microbial growth on both control and test plates. After inoculums absorption by agar, sterile discs of Whatman No. 6 paper (4 mm diameter) previously cleaned with ethanol, were impregnated with a fixed volume of $5 \mu \mathrm{L}$ of undiluted EOs, with or without $5 \% \mathrm{MeOH}$ and $5 \% \mathrm{EtOH}$. A control was used for each case by not exposing the bacteria to any distilled product. Discs were deposited at equal distance on the surface of the agar. The Petri dishes were left at room temperature for $5 \mathrm{~min}$ before incubation to ensure a good diffusion of the distilled product in the agar. Cultures were then incubated at $37^{\circ} \mathrm{C}$ overnight. The activity of essential oils was considered to be positive when inhibitory action of the bacteria was observed and negative when it was not. After the incubation period, the diameters of the inhibition zones were measured in millimetres.

\section{Supplementary data}

Chromatographs 1a to 1e can be found in the supplementary data as well as the anti-bacteria tests.

\section{Acknowledgments}

The authors would like to thank Aucencio Domenzain Martinez for his valuable help and fruitful discussion on Lavender, and Lee Gentry and Azul Lavanda, S.P.R. in Dolores Hidalgo, Mexico, for providing the essential oils. We thank the Genomics service of Langebio for its financial support and "La region de Rennes" for financing Alizé Pennec's PhD and mobility grants.

\section{References}

1. Candan, F.; Unlu, M.; Tepe, B.; Daferera, D.; Polissiou, M.; Sokmen, A.; Akpulat, H. A. J. Ethnopharmacol. 2003, 87, 215-220.

2. Karakaya, S.; El, S. N.; Karagozlu, N.; Sahin, S. J. Med. Food. 2011, 14, 645-652.

3. Molinos, A. C.; Abriouel, H.; Lopez, R. L.; Ben Omar, N.; Valdivia, E.; Galvez, A. Food Chem. Toxicol. 2009, 47, 2216-2223.
4. FDA/USDA/CDC Salmonella-2001 Report; United States Department of Agriculture: (2001).

5. Peana, A. T.; D’Aquila, P. S.; Panin, F.; Serra, G.; Pippia, P.; Moretti, M. D. Phytomedicine. 2002, 9, 721-726.

6. Peana, T.; Moretti, M. D. L. Pharmacological activities and applications of Salvia scalarea and Salvia desoleana essential oils. in: Atta-ur-Rahman (ed.) Series Studies in Natural product Chemistry. 2002, Vol. 26. Bioactive Natural Products, Part G Elsevier Science Publishers, Amsterdam; 391-424.

7. Tzakou, O.; Pitarokili, D.; Chinou, I. B.; Harvala, C. Planta Med. 2001, 67, 81-83.

8. Rasooli, I. Food 2007, 1, 111-136.

9. Legentil, L.; Audic, J-L.; Daniellou, R.; Nugier-Chauvin, C.; Ferrieres, V. Carbohyd. Res. 2011, 346, 1541-1545.

10. Kaikabo, A. A.; Eloff, J. N. J. Ethnopharmacol. 2011, 138, 253255.

11. Bombarda, I.; Dupuy, N.; Da, J. P.; Gaydou, E. M. Anal. Chim. Acta 2008, 613, 31-39.

12. Won, M. M.; Cha, E. J.; Yoon, O. K.; Kim, N. S.; Kim, K.; Lee. D. S. Anal. Chim. Acta. 2009, 631, 54-61.

13. Casale, M.; Armanino, C.; Casolino, C.; Forina, M. Anal. Chim. Acta 2007, 589, 89-95.

14. Lis-Balchin, M. (2002) Lavender: The Genus Lavandula (Medicinal and Aromatic Plants - Industrial Profiles). Taylor \& Francis, London.

15. Boeckelmann, A. (2008) Monoterpene production and regulation in (Lavandula angustifolia and Lavandula x intermedia). University of British Columbia, Okanagan.

16. Politeo, O.; Jukic, M.; Milos, M. Croat. Chem. Acta 2006, 79, 545-552.

17. Derwich, E.; Benziane, Z.; Boukir, A. Aust. J. Basic Appl. Sci. 2009, 3, 3818-3824.

18. Jiang, Y.; Wu, N.; Fu, Y. J.; Wang, W.; Luo, M.; Zhao, C. J.; Zu, Y. G.; Liu, X. L. Environ. Toxicol. Phar. 2011, 32, 63-68.

19. Jalali-Heravi, M.; Moazeni, R. S.; Sereshti, H. J. Chromatogr. A. 2011, 1218, 2569-2576.

20. Baratta, M. T.; Dorman, H. D. J.; Deans, S. G.; Figueiredo, A. C.; Barroso, J. G.; Ruberto, G. Flavour Frag. J. 1998, 13, 235-244.

21. Earl, E. A.; Altaf, M.; Murikoli, R. V.; Swift, S.; O'Toole, R. BMC Complem. Altern. Med. 2010, 10, 25.

22. Gupta, V. K.; Shukla, C.; Bisht, G. R. S.; Saikia, D.; Kumar, S.; Thaku, R. L. Lett. Appl. Microbiol. 2011, 52, 33-40.

23. Suhail, M. M.; Wu, W.; Cao, A.; Mondalek, F. G.; Fung, K. M.; Shih, P. T.; Fang, Y. T.; Woolley, C.; Young, G.; Lin, H. K. BMC Complem. Altern. Med. 2011, 11, 129.

24. Domokos, J.; Héthelyi, E. V.; Pálinkás, J.; Szirmai, S.; Tulok, H. J. Essent. Oil Res. 1997, 9, 41-45.

25. Kalemba, D.; Kunicka, A. Curr. Med. Chem. 2003, 10, 813-829.

26. Akgül, A.; Kivanç, M.; Bayrak, A. J. Essent. Oil Res. 1989, 1, 277-280.

27. Viuda-Martos, M.; Mohamady, M. A.; Fernandez-Lopez, J.; Abd ElRazik, K. A.; Omer, E. A.; Perez-Alvarez, J. A.; Sendra, E. Food Control. 2011, 22, 1715-1722.

28. Cosentino, S.; Tuberoso, C. I.; Pisano, B.; Satta, M.; Mascia, V.; Arzedi, E.; Palmas, F. Lett. Appl. Microbiol., 1999, 29, 130-135.

29. Karaman, I.; Sahin, F.; Gulluce, M.; Ogutcu, H.; Sengul, M.; Adiguzel, A. J. Ethnopharmacol. 2003, 85, 231.

30. NIST/EPA//NIH Mass Spectral Libray 2.0d.

31. Kovats, E. S. Adv. Chromatogr. 1965, 1, 229-247.

32. Jennings, W.; Shibamoto, T. (1980) Qualitative analysis of flavour and fragance volatiles by glass-capillary gas chromatography. Academic Press: New York. 